\title{
Tooth-Supported Prosthodontic Rehabilitation of a Child with Mutilated Dentition: An Interdisciplinary Approach
}

\author{
Hitesh Chander Mittal' Sudhir Bhandari ${ }^{2}$ Ashima Goyal ${ }^{3}$ Krishan Gauba ${ }^{3}$
}

\author{
'Department of Dentistry, Government Medical College, Churu, \\ Rajasthan, India \\ ${ }^{2}$ Unit of Prosthodontics Oral Health Sciences Centre, PGIMER, \\ Chandigarh, India \\ ${ }^{3}$ Unit of Pedodontics and Preventive Dentistry, Oral Health Sciences \\ Centre, PGIMER, Chandigarh, India
}

Address for correspondence: Hitesh Chander Mittal, MDS, Department of Dentistry, Government Medical College, Churu, 331001 Rajasthan, India

E-mail: dr.hiteshmittal@gmail.com

\begin{abstract}
This article describes the interdisciplinary approach for prosthodontic rehabilitation of a four-and-a-half-year-old child reported with mutilated dentition due to S-ECC. The tooth-supported maxillary over-denture was fabricated besides pulpectomies, stainless steel crowns, mandibular incisor celluloid strip crowns, and comprehensive preventive care. The three months followup showed significant improvement in oral function and excellent acclimatization of the child to the prosthesis; however, it needed re-fabrication at 12 months. The real smile on the child's face in this report will encourage the clinicians to seek pediatric prosthodontics despite the need for frequent revisions required to accommodate the growth and development of jaws.
\end{abstract}

Keywords: Child, over-denture, prosthodontics, pediatric dentistry, severe early childhood caries (S-ECC), tooth-supported over-denture

\section{Introduction}

Severe early childhood caries (S-ECC) is a devastating condition that can mutilate the whole dentition of young children in a very short duration of time. Unfortunately, children report's in the advanced stage of S-ECC when there is the requirement of multiple premature extractions to keep the child symptom-free. Severe early childhood caries (S-ECC) is highly prevalent globally and pose serious consequences for the child's quality of life.[1-3] The consequences of untreated S-ECC include multiple episodes of dental pain and infections, poor mastication, delayed physical growth and development, hypoplasia of developing permanent teeth, loss of school days, hampered learning, and compromised self-esteem.[1-5] Also, a child with ECC is more likely to suffer $10 \%$ increased odds of undernutrition with each deep carious tooth.[6]

Treatment of S-ECC is complex, expensive, and due to high caries risk relapses after treatments are common in children managed for S-ECC. Premature extractions of primary teeth further have added psychological trauma, disturbed development of occlusion, diminished oral and general health. Oral health and, thus, generalhealth-related - the quality of life in terms of oral function, episodes of pain, sleep quality, growth and devel-

How to cite this article: Mittal HS, Bhandari S, Goyal A, Gauba K. Tooth-Supported Prosthodontic Rehabilitation of a Child with Mutilated Dentition: An Interdisciplinary Approach. J Pediatr Dent 2021;7(2):93-98 
opment, and self-esteem can be improved with the help of prosthodontic rehabilitation for such cases.[7-9]

The prosthodontic rehabilitation of a child requires a prosthodontist familiar with pediatric prosthodontics and pediatric dentist to work together for a successful outcome. There have been very few reports on prosthetic rehabilitation with access over post system or tooth-supported over-denture.

The purpose of this article is to report the interdisciplinary approach for tooth-supported prosthodontic rehabilitation of a child reported with mutilated dentition due to S-ECC.

\section{Case Presentation}

A four-and-a-half-year-old female child with severe early childhood caries reported with intermittent episodes of dental pain and facial swelling, poor mastica- tion, poor esthetics, and low self-esteem (Fig. 1). The comprehensive preventive care and prosthodontic rehabilitation were planned, and written informed consent was taken from the parents. As part of the comprehensive preventive program, the five-day diet diary analysis revealed the child's diet was limited to milk tea, biscuits, and occasionally chapatti (bread), and thus a diet was prescribed to achieve a balanced diet. The comprehensive preventive care led to termination levels in terms of plaque control, gingival health, modified Snyder test (Snyder test modified by Alban)[10-12], which uses commercially available B-C-G dextrose agar (Snyder Test Agar: Hi Media Laboratories PVT Ltd, Mumbai) (Fig. 2), and S. mutans count (Dentocult SM, Orion Diagnostica, Helsinki, Finland). The Mutans Streptococci counts seen using the Dentocult SM kit was compared to the standard interpretation chart provided by the manufacturer. The modified Snyder test
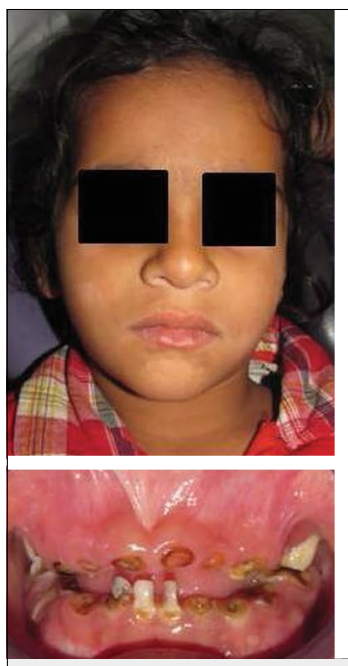
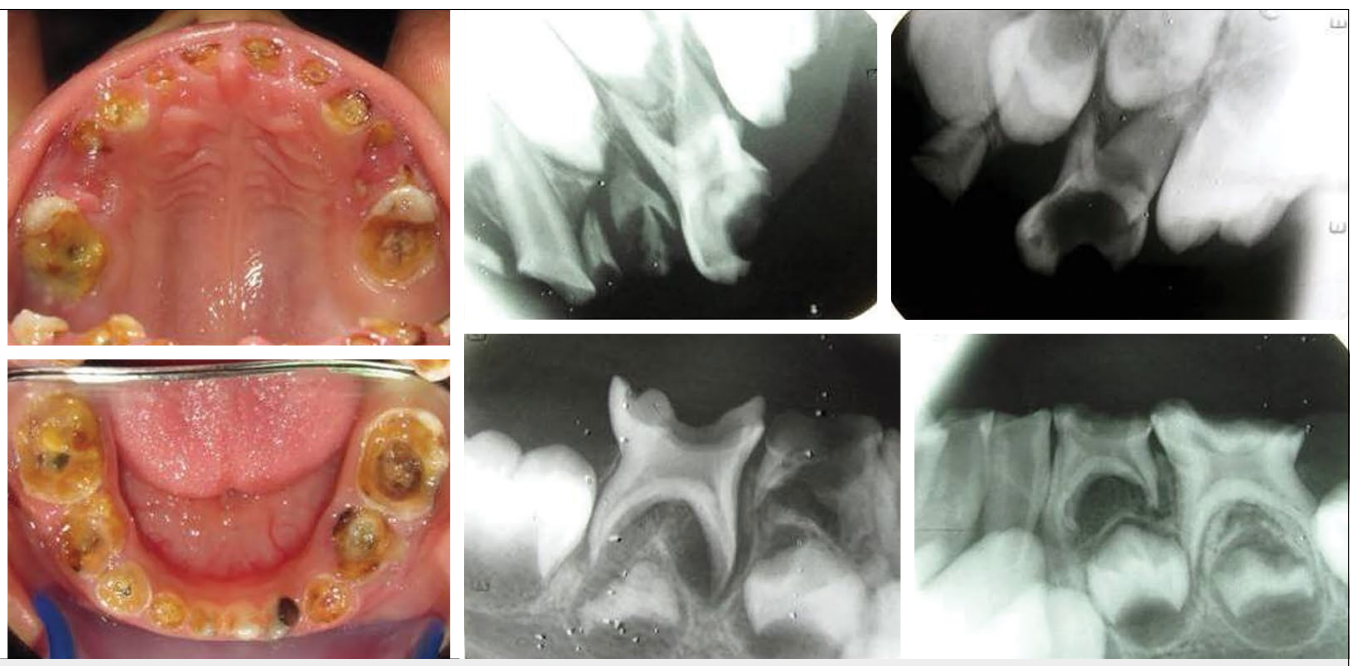

Figure 1. Clinical and radiographic profile of child at the time of presentation
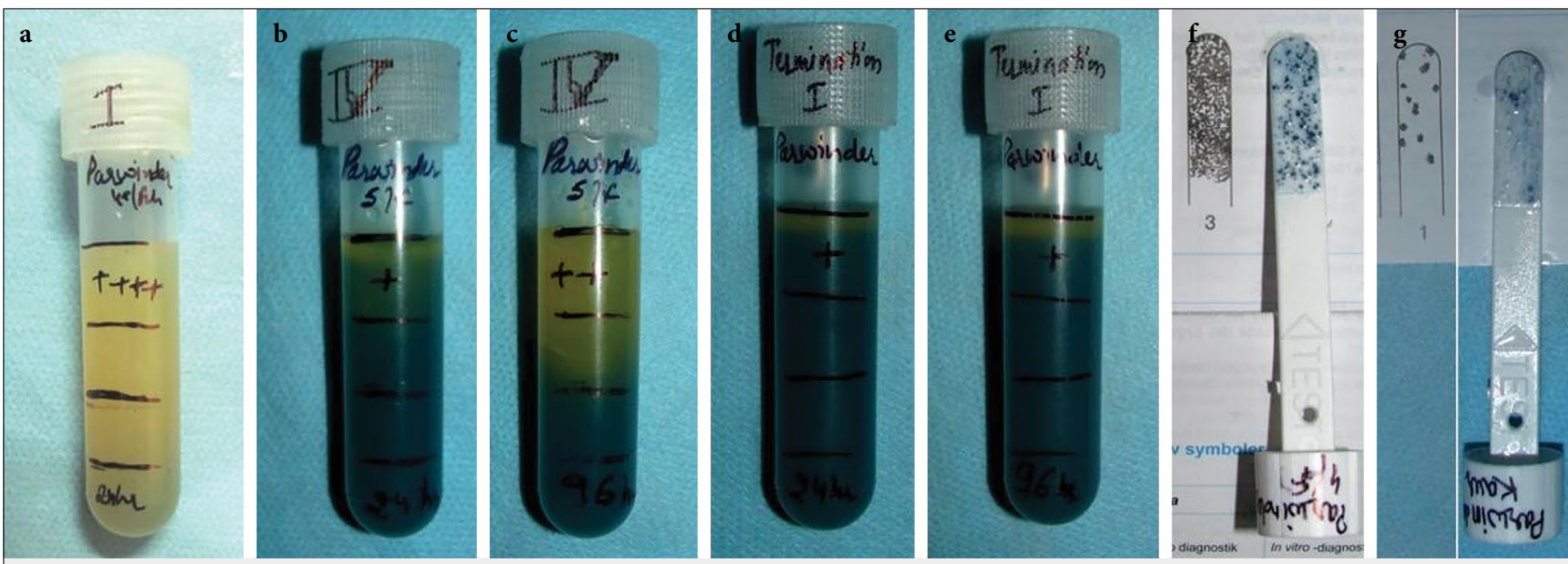

Figure 2. Modified Snyder test after incubation (a) baseline at 24 hrs; (b, c) after rehabilitation at 24 hrs and 96 hrs; (d, e) termination level at $24 \mathrm{hrs}$ and $96 \mathrm{hrs}$ (f, g) Dentocult SM at baseline and at termination level 
Table 1. Interpretation of modified Snyder test ${ }^{\#}$

\begin{tabular}{|c|c|c|c|c|}
\hline \multirow[t]{2}{*}{ Observation time of Snyder media } & \multicolumn{4}{|c|}{ Caries activity grades } \\
\hline & Nil & Mild & Moderate & Severe \\
\hline $24 \mathrm{hr}$ & - & - & - & + \\
\hline $48 \mathrm{hr}$ & - & - & + & ++ \\
\hline $72 \mathrm{hr}$ & - & + & ++ & +++ \\
\hline $96 \mathrm{hr}$ & + & ++ & +++ & ++++ \\
\hline
\end{tabular}

\# +: color change till upper $1 / 4^{\text {th }}$ length of Snyder media, ++ : color change till upper $1 / 2$ length of Snyder media, +++ : color change till upper $3 / 4^{\text {th }}$ length of Snyder media, ++++: color change full length of Snyder media

was interpretation as per Table 1.[11,12] All un-restorable root stumps were extracted. Pulpectomy treatment was carried out for 75, 85, 65, 53, 63, 73, 83, 72 followed by stainless steel crowns for $75,85,65$. The maxillary celluloid strip crowns were used for mandibular incisors $(71,81)$. The maxillary over-denture prosthesis was fabricated using child's friendly modifications and different behavior management techniques (Fig. 3). The preliminary cast was used for acrylic resin tray fabrication, and the final impression was made with light body polysiloxane material (AFFINIS, Coltene/Whaledent AG, Switzerland). The lips and cheeks were manipulated to properly record functional border molded mucobuccal fold. Thus, the final cast was poured in dental stone, shellac base plate adaptation, and occlusal wax rim fabricated. The centric positions of the jaws were recorded using clinical methods, and working models were mounted on an articulator. Custom-made pediatric teeth were used for teeth arrangement to mimic primary dentition. The maxillary denture was processed in heat-curing acrylic resin. Access post-over-denture system was used with direct/non-coping technique. Overpost cemented in the root canal of maxillary primary canines ( $3 \mathrm{~mm}$ extension) without any post-space preparation (Fig. 4). Nylon caps corresponding to the ball of the post were secured with chemical cure acrylic in the maxillary denture. Mandibular removable treatment denture with clasp was fabricated in heat-curing acrylic resin (Fig. 3). Occlusion checked and adjusted followed by finishing and polishing of dentures.
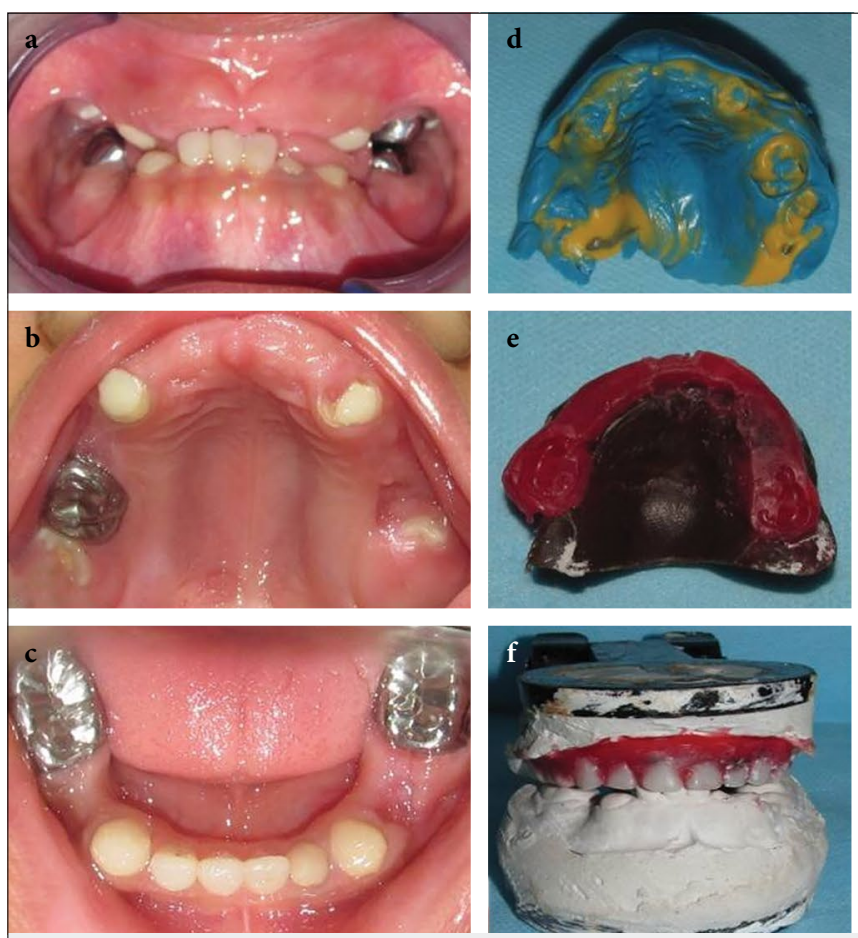
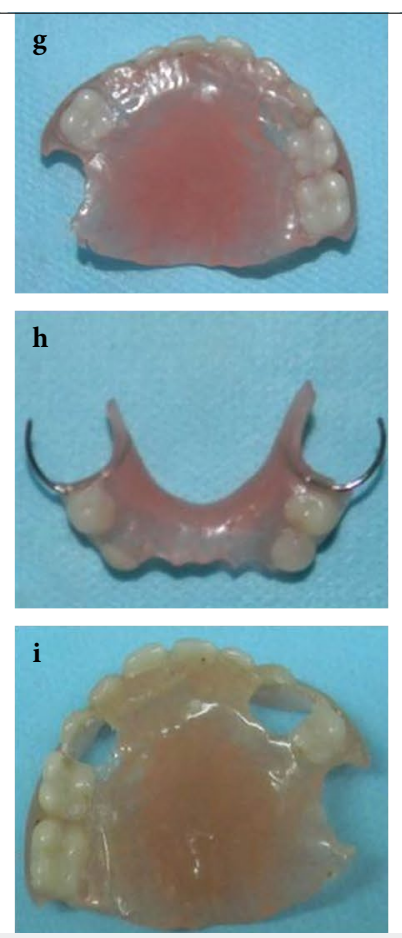
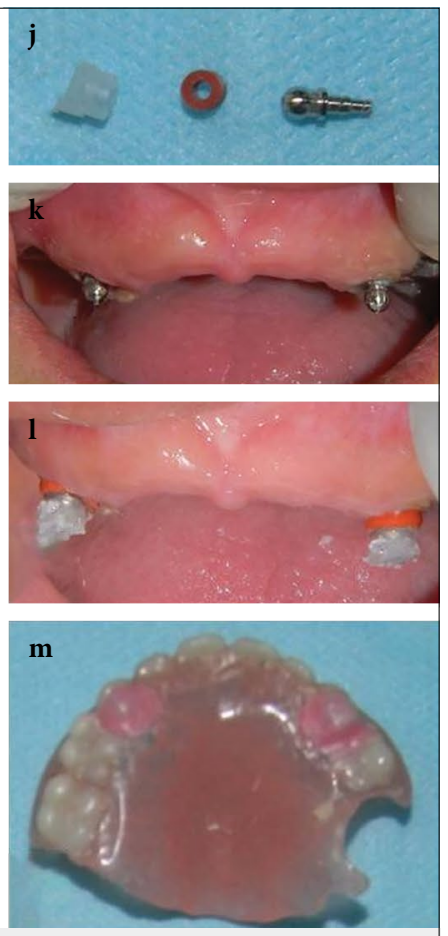

Figure 3. (a-c) Clinical after extraction of un-restorable primary teeth, placement of strip crowns and Stainless steel crowns; (d) Final maxillary impression with light-body vinyl polysiloxane material in custom trays; (e, f) Custom fabricated age appropriate teeth arrangement on articulated shellac base occlusal rim; $(\mathrm{g}, \mathrm{h})$ Heat cure processed maxillary and mandibular prosthesis; (i-m) Access post-over-denture system cementation and nylon caps secured in the maxillary denture with cold cure acrylic 
Parents and child were taught denture insertion and maintenance. The palatal extension of the maxillary denture was trimmed to make it horseshoe-shaped due to complaints of discontentment in eating food on oneweek follow-up. The 3 months follow-up showed guidance for erupting permanent first molars (Fig. 5), and the patient's mother reported excellent acclimatization of the child to the prosthesis as well as improvements in her dietary habits, speech, and self-image. Over 12 months, the maxillary denture was not fitting well and needed re-fabrication.

\section{Discussion}

Oral health is an essential component of total health and well-being. Children with S-ECC were more likely to have poor physical, mental, and social functioning as compared to caries-free children.[1,13] Prosthodontic
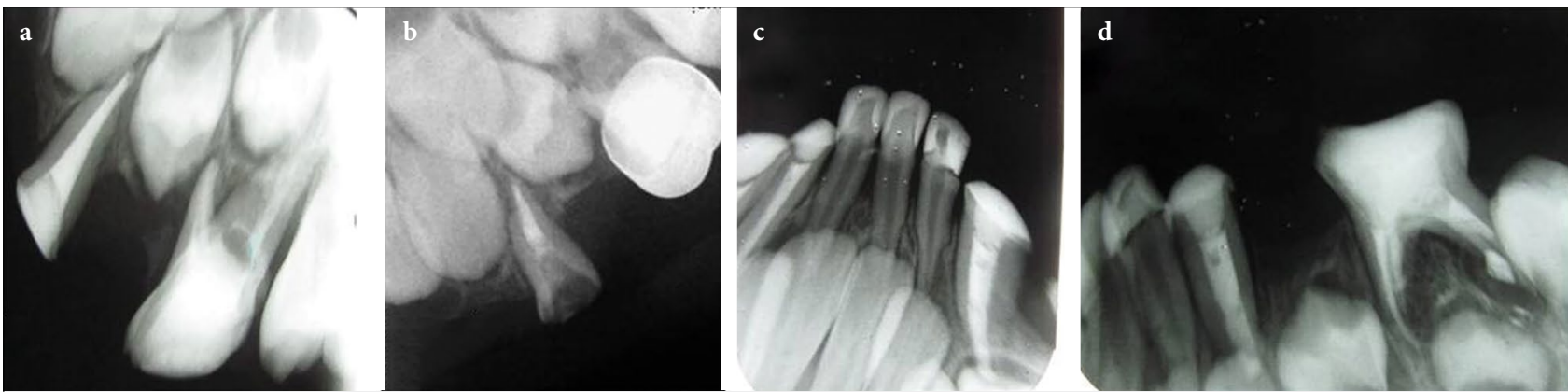

Figure 4. Radiographic profile (a) Post-obturation view of maxillary canine; (b) Radiographic view of maxillary canine showing post space and Glass ionomer cement lining sealing obturation material, (c) Radiographic view of mandibular anterior teeth restored with strip crowns, (d) Post-obturation view of mandibular molar
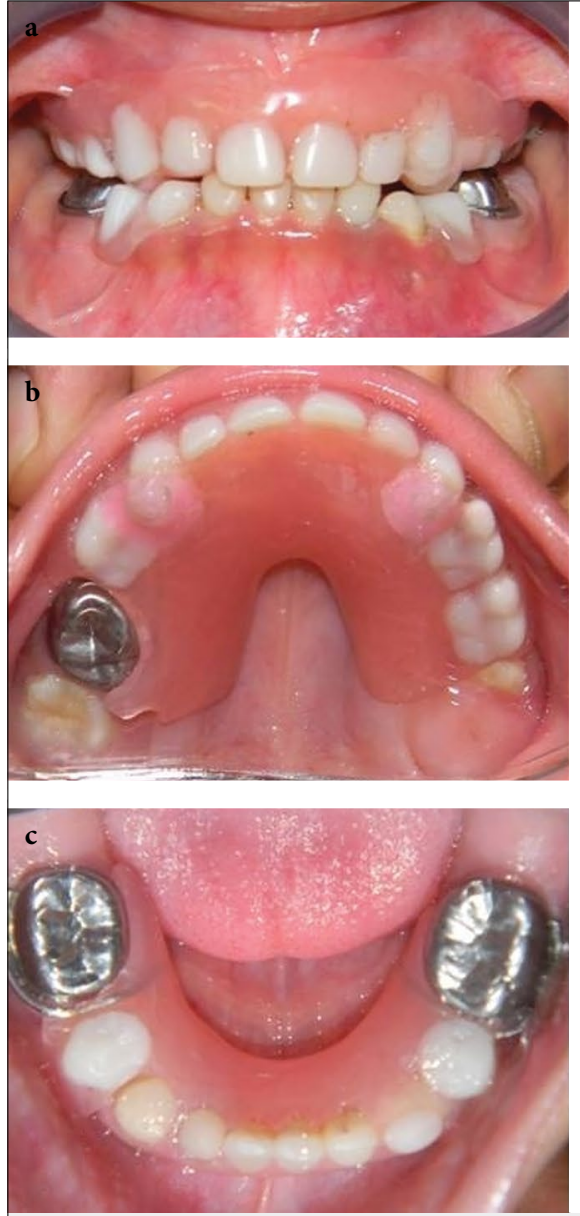
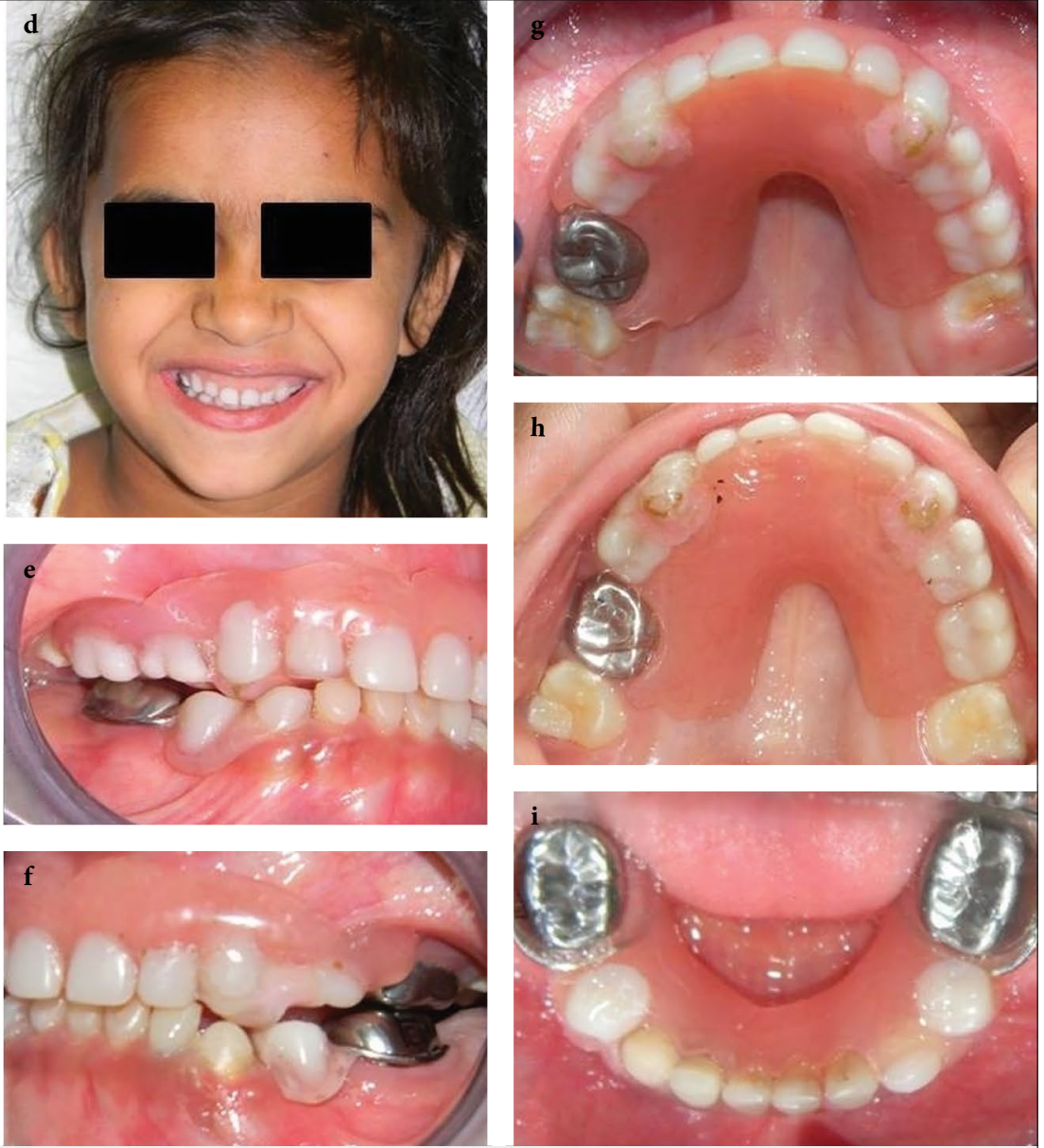

Figure 5. Postoperative clinical profile (a-c) one week after insertion; (d-g) 3 months post-insertion; (h, i) 6 months post-insertion 
rehabilitation for children with multiple un-restorable teeth is a viable treatment option in young children to provide esthetic, phonetic, and masticatory units and to prevent psychological trauma. $[9,14]$ The phenomenon of catch-up growth has been reported to occur in children, whose growth had been slowed down by malnutrition following the complete dental intervention.[15] The prosthodontic rehabilitation of children is challenging and requires excellent child and parent cooperation for successful fabrication, prosthesis hygiene maintenance, periodic revisions (every 2 to 4 years), and handling to avoid breakage of the denture.[16] Also, there is a need to be quick and accurate with prosthesis fabrication steps and well versed with behavior modification techniques which can be achieved when the pediatric dentist and prosthodontist combinedly work as a team. The tedious and long process of removable prosthesis fabrication can be accomplished by motivation and education of parents, and simplifying the fabrication process to a level acceptable to child meanwhile ensuring adequate retention, and esthetics for post-insertion good compliance.[16,17] Also, parent's education regarding temporary changes in enunciation, mastication, and swallowing affects pediatric prosthesis success. A lot of work has been done on prosthodontic rehabilitation of anodontia due to congenital anomalies in children. However, limited literature exists for the rehabilitation of mutilated dentition due to S-ECC.

The advantages of an over-denture vis-a-vis conventional total prosthesis are increased stability and support, accentuation of the mechanism of muscle "feedback" and proprioception, increased comfort during chewing and speaking, and also the preservation of the tooth and the alveolar bone.[18] The tooth-supported over-dentures offer an increased denture retention due to the cementation of intra-canal posts with attachments in endodontically treated teeth. $[8,18]$ Mattuella et al[8] used an orthodontic expansion screw to the denture midline to accommodate the child's maxillofacial development, and no alteration of denture adaptation was found with 18 months of use. Over-denture also acts as a functional space maintainer that allows eruption of the permanent teeth by perforating the denture base.

Children with a history of ECC are highly susceptible to relapse after oral rehabilitation.[19] Thus, caries risk management, as well as preventive strategies to restore oral biofilm homeostasis, are important.[20] Caries activity as per Snyder test and mutans streptococci levels in saliva are good screening methods to identify high-risk children.[12] Modified Snyder test assesses the acidogenic potential of saliva, rapidity of acid formation in the oral cavity, and indirect quantitative assessment of acidogenic and aciduric bacteria which can grow and produce acid in the Snyder agar. $[10,12]$ The time and extent of the color change of Snyder medium determine the conduciveness of the diet which was used for diet counseling and for monitoring the effectiveness of a preventive program.[10] In a study by Ramesh et al, the sensitivity and negative predictive value of Snyder's test was found to be $87.5 \%$ in caries-free individuals and $100 \%$ sensitivity in children with dental caries.[21] Sánchez-Pérez et al reported that Snyder's test could identify 95\% of children in the low risk category and $84 \%$ of children in the high risk dental caries category.[22]

Dentocult SM, simple test kit has been used[12,2325] for practical semi-quantitative detection of the mutans streptococci levels, and their high proportions may be considered as biomarkers of rapid caries progression.[23] According to the literature, the sensitivity of the chair-side test for mutans streptococci is $44-71 \%$ and in general, it is lower than the specificity taken as 56-100\%.[23] However, the caries predictive power increases when these tests are included in multi-factorial models for caries prediction.[23] Li et al[24] labeled it as reliable for caries risk assessment and found that children having $\mathrm{S}$. mutans count of $>10^{6} \mathrm{CFU} / \mathrm{ml}$ saliva is 6 to 8 times more likely to develop dental caries at the age of 5 years.[24] In contrast, Pilbauerova et al[25] reported differences existed in caries increment among children with different Dentocult SM test scores. The chair-side test for mutans streptococci is also justified for preschool children, as delayed colonization of mutans streptococci is associated with reduction in dental caries.[23]

As part of the comprehensive preventive program, the dietary prescription, as well as knowledge of the disease process, resulted in good dietary habits which were initially shifted to sweet and soft diet due to poor masticatory units. In this high-risk case, the implementation of a comprehensive preventive program was effective in achieving termination levels assessed using modified Snyder test, and Dentocult SM test indicating oral biofilm homeostasis.

The preventive program, behavior modifications, pediatric restorative and prosthodontic rehabilitation of a young child with mutilated dentition resulted in significant improvement in the child's oral-healthrelated quality of life such as the resolution of pain and infection, improved appearance, self-image, adequate 
mastication, improved dietary habits, and guidance for erupting teeth. The prosthetic rehabilitation led to a real smile on the child's face which is the justification for the tedious process of pediatric prosthodontics and will encourage the clinicians to seek pediatric prosthodontics. Though, the limitation of prosthodontic rehabilitation is the need for frequent revisions as required at one year in this present case. Pediatric prosthodontics needs further research work to reduce the need for frequent revisions required to accommodate the growth and development of jaws.

Financial Disclosure: Nil.

Conflict of Interest: None declared.

\section{References}

1. Chai HH, Gao SS, Chen KJ, Duangthip D, Lo ECM, Chu $\mathrm{CH}$. A kindergarten-based oral health preventive approach for Hong Kong preschool children. Healthcare (Basel) 2020;8(4):545 doi:10.3390/healthcare 8040545

2. Sheiham A. Dental caries affects body weight, growth and quality of life in pre-school children. Br Dent J 2006;201(10):625-626 doi:10.1038/sj.bdj.4814259

3. Renggli EP, Turton B, Sokal-Gutierrez K, et al. Stunting malnutrition associated with severe tooth decay in Cambodian toddlers. Nutrients 2021;13(2):290 doi:10.3390/nu13020290

4. Poureslami HR, Van Amerongen WE. Early Childhood Caries (ECC): an infectious transmissible oral disease. Indian J Pediatr 2009;76(2):191-194 doi:10.1007/s12098-008-0216-1

5. Schroth RJ, Harrison RL, Moffatt ME. Oral health of indigenous children and the influence of early childhood caries on childhood health and well-being. Pediatr Clin North Am 2009;56(6):14811499 doi:10.1016/j.pcl.2009.09.010

6. Athavale P, Khadka N, Roy S, et al. Early childhood junk food consumption, severe dental caries, and undernutrition: A mixed-methods study from Mumbai, India. Int J Environ Res Public Health 2020;17(22):8629 doi:10.3390/ijerph17228629

7. Tannure PN, Moraes GG, Borba M, Abrahão A, Andrade M, Fidalgo T. Prosthetic oral rehabilitation of a child with S-ECC: A case report with histopathologic analysis. J Clin Pediatr Dent 2015;39(5):410-414 doi:10.17796/1053-4628-39.5.410

8. Mattuella LG, Frasca LC, Bernardi L, Moi GP, Fossati AC, de Araújo FB. Tooth supported prosthetic rehabilitation in a 5-year-old child with early childhood caries. J Clin Pediatr Dent 2007;31(3):171-174 doi:10.17796/jcpd.31.3.vn33891816723523

9. Sacramento PA, de Castilho AR, Frasseto F, Gaviao MB, Nobredos-Santos M, Rontani RM. One-year clinical evaluation of oral rehabilitation after the loss of multiple primary teeth. Gen Dent 2011;59(3):230-233

10. Alban A. An improved Snyder test. J Dent Res 1970;49(3):641 doi :10.1177/00220345700490033501

11. Gauba A, Bal IS, Jain A, Mittal HC. School based oral health promotional intervention: Effect on knowledge, practices and clinical oral health related parameters. Contemp Clin Dent 2013;4(4):493-499 doi:10.4103/0976-237X.123056

12. Shashni R, Goyal A, Gauba K, Utreja AK, Ray P, Jena AK. Comparison of risk indicators of dental caries in children with and without cleft lip and palate deformities. Contemp Clin Dent 2015;6(1):58-62 doi:10.4103/0976-237X.149293

13. Cunnion DT, Spiro A 3rd, Jones JA, et al. Pediatric oral health-related quality of life improvement after treatment of early childhood caries: a prospective multisite study. J Dent Child (Chic) 2010;77(1):4-11

14. Parisotto TM, de Souza-E-Silva CM, Steiner-Oliveira C, Nobredos-Santos M, Gavião MB. Prosthetic rehabilitation in a fouryear-old child with severe early childhood caries: a case report. J Contemp Dent Pract 2009;10(2):90-97

15. Acs G, Shulman R, Ng MW, Chussid S. The effect of dental rehabilitation on the body weight of children with early childhood caries. Pediatr Dent 1999;21(2):109-113

16. Hugar SM, Shigli AL, Ravindranath Reddy PV, Roshan NM. Prosthetic rehabilitation of a preschooler with induced anodontia - A clinical report. Contemp Clin Dent 2011;2(3):207-210 doi:10.4103/0976-237X.86462

17. Bidra AS, Martin JW, Feldman E. Complete denture prosthodontics in children with ectodermal dysplasia: review of principles and techniques. Compend Contin Educ Dent 2010;31(6):426-444

18. Bolan M, Cardoso M, Galato G, Vieira Rde S, Andriani W Jr. Overdenture for total rehabilitation in a child with early childhood caries. Pediatr Dent 2012;34(2):148-149

19. Berkowitz RJ, Amante A, Kopycka-Kedzierawski DT, Billings RJ, Feng C. Dental caries recurrence following clinical treatment for severe early childhood caries. Pediatr Dent 2011;33(7):510-514

20. Marsh PD, Percival RS. The oral microflora--friend or foe? Can we decide?. Int Dent J 2006;56(4 Suppl 1):233-239 doi:10.1111/ j.1875-595x.2006.tb00107.x

21. Ramesh K, Kunjappan S, Ramesh M, Shankar S, Reddy S. Comparative evaluation of predictive value of three caries activity tests-snyder, lactobacillus count and cariostat in mixed dentition children with and without caries. J Pharm Bioallied Sci 2013;5(Suppl 1):S63-S68 doi:10.4103/0975-7406.113299

22. Sánchez-Pérez L, Acosta-Gío AE, Méndez-Ramírez I. A cluster analysis model for caries risk assessment. Arch Oral Biol 2004;49(9):719-725 doi:10.1016/j.archoralbio.2004.02.012

23. Lenčová E, Broukal Z, Spížek J. Point-of-care salivary microbial tests for detection of cariogenic species--clinical relevance thereof--review. Folia Microbiol (Praha) 2010;55(6):559-568 doi:10.1007/s12223-010-0090-x

24. Li Y, Saraithong P, Chen Z, Leung E, Pattanaporn K, Dasanayake A. Comparison of real-time quantitative PCR with a chairside test for streptococcus mutans assessment. Chin J Dent Res 2017;20(4):199-210 doi:10.3290/j.cjdr.a39219

25. Pilbauerova N, Cermakova E, Koberova Ivancakova R, Suchanek $\mathrm{J}$. The association of caries increment dynamics in preschool children with risk factors: The 3-year prospective study. Int J Environ Res Public Health 2020;17(20):7459 doi:10.3390/ijerph17207459 